\title{
PERSPECTIVAS SOBRE $O$ EMPREENDEDORISMO INFORMACIONAL NA CIÊNCIA DA INFORMAÇÃO
}

\author{
PERSPECTIVES ABOUT INFORMATION \\ ENTREPRENEURSHIP IN INFORMATION SCIENCE \\ FIELD
}

Beatriz Rosa Pinheiro dos Santos ${ }^{a}$

Selma Leticia Capinzaiki Ottonicarb

leda Pelogia Martins Damianc

\begin{abstract}
RESUMO
Introdução: O artigo objetiva iniciar discussões sobre o tema do empreendedorismo informacional como um novo processo da Ciência da Informação. Tal objetivo está relacionado aos seguintes questionamentos: o que é empreendedorismo informacional? O empreendedorismo informacional pode contribuir para o processo da gestão da informação? A metodologia é de natureza qualiquantitativa, do tipo descritivoexploratória, que utiliza as técnicas de análise bibliográfica e de análise cientométrica para demonstrar como o empreendedorismo informacional é abordado pela Ciência da Informação, bem como sua relação com a gestão da informação. Os resultados demonstraram que os estudos ainda são escassos na área e, portanto, existem oportunidades de pesquisa sobre a temática. Além disso, demonstrou-se a inter-relação entre o empreendedorismo informacional com a gestão da informação e o quanto essa conexão contribui para que as organizações se tornem mais competitivas e obtenham melhores resultados. As considerações finais apontam que o empreendedorismo informacional está relacionado com a criação de novos negócios e procedimentos no processo produtivo e se serviço, mediante o uso da informação para a construção de conhecimento e geração de lucros.
\end{abstract}

Descritores: Empreendedorismo informacional. Gestão da Informação. Ciência da Informação. Análise Cientométrica.

a Doutoranda no Programa de Pós-Graduação e Ciência da Informação da Universidade Estadual Paulista Júlio de Mesquita Filho (UNESP). E-mail: pinheiro.santos@unesp.br.

b Doutora no Programa de Pós-Graduação e Ciência da Informação da Universidade Estadual Paulista Júlio de Mesquita Filho (UNESP). E-mail: selma.leticia@hotmail.com selma.leticia@unesp.br.

c Doutorado em Administração de Organizações pela Universidade de São Paulo (USP), Professora da Universidade Estadual Paulista (UNESP) e da Universidade de São Paulo (USP). E-mail: ieda.martins@unesp.br. 


\section{INTRODUÇÃO}

Que a informação se tornou um recurso primordial no ambiente das organizações, todos já sabem, que necessita ser gerenciada para uso nos processos decisórios e obtenção natural de maiores lucros, também. Todavia, apenas saber e estar consciente da sua importância não é o suficiente. É visto como necessária a adoção de práticas, novos e diferentes processos para real gestão e uso da informação nas distintas demandas e necessidades informacionais de uma organização.

A Ciência da Informação $(\mathrm{Cl})$ como campo científico responsável por estudar a informação nas suas mais diversas formas, alavancar suas nuances e analisá-la em prol da sua aplicação efetiva nas situações de urgências e exigências das organizações e das pessoas, encontra-se em constante aprimoramento, devido a sua capacidade flexível de receber contribuições, novos modelos e reflexões que possam auxiliar no crescimento e popularização do campo, bem como na ideia de valorização da informação por via do espectro organizacional e social.

Diversos temas vêm sendo trabalhados na área da $\mathrm{Cl}$, com o intuito de apoiar o desenvolvimento do campo, tais quais: 'epistemologia da Ciência da Informação', 'organização e representação do conhecimento', 'mediação e apropriação da informação', 'gestão da informação', 'gestão do conhecimento', 'política da informação' 'economia da informação', 'produção e comunicação da informação', 'preservação da informação em ambientes digitais', 'memória da informação', 'informação em saúde', 'informação em museu e patrimônio', entre muitos outros temas inseridos nestes como outros processos de estudo da informação.

Com tantas pesquisas oriundas de diferentes temas sendo desenvolvidas, em um único campo científico, entretanto, com o mesmo objetivo, que consiste em fortalecer o papel da $\mathrm{Cl}$ na sociedade, torna-se possível inferir e até em afirmar que a $\mathrm{Cl}$ é vasta e consistente mesmo em constantes mudanças e aprimoramentos.

A fim de fomentar ainda mais o desenvolvimento da área, surge um outro 
tema, que pode vir a ser considerado um processo da $\mathrm{Cl}$, chamado de "empreendedorismo informacional", que se estabelece como fruto da interdisciplinaridade existente entre o campo da Administração e da Ciência da Informação, e que, assim como a gestão da informação e a gestão do conhecimento, pode contribuir de maneira significativa para o desenvolvimento efetivo de práticas organizacionais, que por sua vez, devem se basear em informação de qualidade.

Com isso, o objetivo deste trabalho é iniciar discussões sobre o tema do empreendedorismo informacional como um novo processo da Ciência da Informação, concomitantemente, respondendo aos seguintes problemas de pesquisa: o que é empreendedorismo informacional? $\mathrm{O}$ empreendedorismo informacional pode contribuir para o processo da gestão da informação?

Para o alcance das respostas e do objetivo geral do trabalho, adotou-se o desenvolvimento de uma pesquisa descritivo-exploratória, de natureza qualiquantitativa, e de cunho teórico, que utiliza a análise bibliográfica e a análise cientométrica como metodologia de pesquisa.

\section{CAMPO DA CIÊNCIA DA INFORMAÇÃO}

Antes da conceituação de Ciência da Informação, é fundamental o entendimento da palavra "informação", pois este campo analisa a informação e as ações que a permeiam em diferentes contextos. Muitos são os autores que atribuíram significado à informação, tais como Borko (1968), Saracevic (1995), Capurro e Hjordland (2007), Logan (2012), entre outros.

A informação, segundo Saracevic (1995, p. 41), é aquilo emitido na comunicação, não obstante é um conceito autoexplicativo. O autor Logan (2012, p. 8) raciocina mais a fundo sobre o conceito de informação, pois observa que há uma ironia em relação à imersão total do ser humano com a informação; apontando que a informação possui um papel central na vida econômica, humana e social e, entretanto, os indivíduos não possuem um entendimento claro do que é informação. Sendo assim a informação não pode ser definida de uma maneira simples ou direta, mas é uma ideia "escorregadia", uma vez que é 
empregada de modos diferentes.

Desse modo, como apontam Capurro e Hjordland (2007), o uso comum da palavra informação pode apresentar significados distintos de sua definição formal, e, como consequência, existem teorias que divergem entre si sobre as definições científicas explícitas e implícitas de uso comum.

Ao longo da história, o ser humano tenta associar as formas de classificar, registrar, organizar e difundir a informação nas múltiplas áreas do conhecimento. Entretanto, havia a necessidade de uma área especifica que lidasse com os problemas da informação enquanto fenômeno social (SILVA; FREIRE, 2012).

A Ciência da Informação surge com a perspectiva de atender áreas do conhecimento profissional e cientifico de nível superior ou não, pessoas, entidades sociais, políticas, econômicas, culturais e educativas (SILVA; FREIRE, 2012).

A visão de que a informação e o conhecimento são imprescindíveis para a rotina organizacional se iniciou a partir de 1970, perante um novo modelo tecnológico construído nos Estados Unidos. Essa visão possibilitou o desenvolvimento de novos estilos de comunicação, produção, gestão e um novo estilo de vida dos indivíduos. (CASTELLS, 2005).

Ressalta-se que a informação e o conhecimento acompanham o homem desde os primórdios da civilização, o que pode ser comprovado por meio da observação do desenvolvimento do cérebro e das transcrições de períodos, como, por exemplo, da pedra lascada para a pedra polida.

Como defendem Capurro e Hjorland (2007), ainda que o conhecimento e sua comunicação fossem elementos básicos desde o início da sociedade, é o aparecimento da tecnologia da informação e seus resultados que descrevem a sociedade atual como sociedade da informação.

Saracevic (1995) defende que a Ciência da Informação não deve ser conceituada apenas pelas definições lexicais ou ontológicas. Nesse sentido, a $\mathrm{Cl}$ é compreendida pelos problemas que possui e pelos métodos escolhidos para a solução desses problemas. Assim, a $\mathrm{Cl}$ possui três características que fundamentam sua existência: interdisciplinar, ligada a TI e participa ativamente na evolução da sociedade da informação. 
A Ciência da Informação investiga as propriedades e o comportamento da informação, os estímulos que conduzem o fluxo de informação, o processamento de informação direcionado ao acesso e uso. Seu foco engloba a origem, coleta, organização, armazenamento, recuperação, interpretação, transmissão, transformação e o uso da informação (BORKO, 1968).

Diante desses fatos históricos, epistemológicos e teóricos, vale ressaltar que não é possível uma definição concreta e única da Ciência da informação, pois, segundo Silva e Freire (2012), por ser uma área do conhecimento transdisciplinar, suas definições advêm de disciplinas complexas e diversificadas, o que dificulta se pensar em uma descrição única.

Por isso, um estudo que aborda o empreendedorismo informacional e a gestão da informação congrega a Administração e a Ciência da Informação de modo interdisciplinar. Não obstante, possibilita que os indivíduos que almejam empreender possam organizar a informação para identificar oportunidades do mercado. Com isso, a tomada de decisão se torna eficaz e influencia positivamente a competitividade organizacional.

\section{EMPREENDEDOR E O EMPREENDEDORISMO: ASPECTOS CONCEITUAIS}

O empreendedor é a pessoa que toma decisão para transformar uma ideia em prática, podendo ser um novo produto ou abertura de negócio. Segundo Schumpeter (1988), o empreendedor contribui para o crescimento econômico. O empreendedorismo é o resultado realizado pelo empreendedor e pode estar relacionado com a criação de um novo negócio, produto ou processo que melhore a organização. Nesse sentido, está relacionado com a inovação organizacional e, para tanto, necessita da aprendizagem criativa para construir conhecimento. Schumpeter (1988, p. 48) explica que "o empreendedor promove a inovação, sendo essa radical, pois destrói e substitui esquemas de produção vigentes. Baseado nessa premissa nasce o conceito de destruição criativa".

$O$ agrupamento de ações que melhora o desempenho da sociedade e traz riqueza também compõe o conceito de empreendedorismo. Esse conceito não 
possui um consenso na literatura de Administração e Economia, pois pode ser estudado por várias áreas do conhecimento. "[...] não haverá desenvolvimento econômico sem que na sua base existam líderes empreendedores" (BAGGIO; BAGGIO, 2014, p. 25).

Hisrich e Peter (2004) apontam a cultura do indivíduo como impulsionador do empreendedorismo, pois as pessoas ao seu redor podem incentivá-lo em direção à criatividade.

Ao se falar em empreendedorismo, automaticamente, pensamos em líderes de sucesso como Bill Gates (Microsoft), Steve Jobs (Apple), Larry Page (Google) e líderes de grandes empresas associadas aos Estados Unidos. Contudo, existem empreendedores de empresas menores que estão presentes na vida das pessoas, como é o caso dos proprietários de quitandas, mercados, padaria, bares, docerias, etc.

O empreendedorismo contribui com o emprego a população, gerando mais renda para a localidade. Esse fenômeno é bastante comum no contexto das Micro e Pequenas Empresas (MPE) que inovam e promovem o crescimento econômico local. Um dos elementos que promovem a inovação é a informação e o conhecimento.

A informação e o conhecimento exercem papel fundamental no processo de inovação, pois o acesso à informação contribui para a construção de conhecimento, que influencia na criatividade. A criatividade colocada em prática gera inovação (OTTONICAR, 2016). A inovação é parte relevante ao empreendedorismo, já que atua no ganho de competitividade e crescimento econômico (SCHUMPETER, 1988; HISRICH; PETER, 2004; ZARPELLON, 2010; BAGGIO; BAGGIO, 2014).

\section{METODOLOGIA}

Esta pesquisa é de natureza qualiquantitativa, do tipo descritivoexploratória, que utiliza as técnicas de análise bibliográfica e de análise cientométrica como metodologia. Trata-se de um estudo teórico desenvolvido com base em material publicado, como livros e artigos científicos, com o intuito 
de refletir sobre o conceito de 'empreendedorismo informacional' inserido no campo da $\mathrm{Cl}$. Além disso, a pesquisa utiliza a cientometria para avaliar a produção brasileira sobre 'empreendedorismo informacional', principalmente no âmbito da $\mathrm{Cl}$.

A pesquisa bibliográfica, de acordo com Fonseca (2002, p.32):

[...] é feita a partir do levantamento de referências teóricas já analisadas, e publicadas por meios escritos e eletrônicos, como livros, artigos científicos, páginas de web sites. Qualquer trabalho científico inicia-se com uma pesquisa bibliográfica, que permite ao pesquisador conhecer o que já se estudou sobre o assunto. Existem, porém pesquisas científicas que se baseiam unicamente na pesquisa bibliográfica, procurando referências teóricas publicadas com o objetivo de recolher informações ou conhecimentos prévios sobre o problema a respeito do qual se procura a resposta (FONSECA, 2002, p. 32).

Portanto, é possível dizer, mediante o expressar de Fonseca (2002), que a análise bibliográfica se constitui em um elemento relevante para qualquer estudo científico, pois desse tipo de análise e material é que se torna possível as ações de reflexão, criação, inovação e empreendimento sobre determinado assunto. A pesquisa somente se desenvolve de modo eficiente se estiver baseada em outras ideias e pensamentos, pois é mediante a sinergia comunicacional e interdisciplinar entre os pesquisadores que se torna viável o crescimento da pesquisa científica brasileira.

Quanto a ideia de utilização da cientometria, pode-se dizer que partiu de uma citação de Callon, Courtial e Penan (1995), que diz que a contagem de publicações científicas é um tipo simples e importante de indicador de atividade, que traz informações sobre a atuação de um campo, a maneira como cresce ou não, e o grau de produtividade dos pesquisadores. Segundo os autores supracitados, a cientometria é uma ciência que estuda as características da produção técnica e acadêmica, do desenvolvimento de patentes, etc. Logo, dispôs-se como essencial o uso desta técnica neste trabalho, justamente pelo fato de estar lidando com um conceito inovador para a área da Ciência da Informação.

Para o desenvolvimento da análise bibliográfica foram utilizadas as seguintes bases de dados: Library and Information Science Abstracts (LISA), Base de Dados Referenciais de Artigos de Periódicos em Ciência da Informação 
(BRAPCI) e Scientific Electronic Library Online (SciELO). Para busca de materiais bibliográficos nas bases de dados nacionais (BRAPCI e SciELO), utilizou-se as palavras-chave: Empreendedorismo. Empreendedorismo Informacional. Ciência da Informação e Gestão da Informação. Para busca e seleção na base de dados internacional (LISA), de materiais que contemplassem o desenvolvimento do referencial teórico do artigo, empregou-se os seguintes termos em inglês: Entrepreneurship. Information Entrepreneurship. Information Science and Information Management.

Para a aplicação da técnica cientométrica foram utilizadas as bases de dados: Library and Information Science Abstracts (LISA), Base de Dados Referenciais de Artigos de Periódicos em Ciência da Informação (BRAPCI) e Scientific Electronic Library Online (SciELO). Para busca de produção científica que abordasse o empreendedorismo informacional nas bases de dados nacionais (BRAPCI e SciELO), utilizou-se os descritores: "Empreendedorismo Informacional" AND "Ciência da Informação". Para busca na base de dados internacional (LISA), empregou-se os seguintes termos em inglês: "Information Entrepreneurship" AND "Information Science".

Pode-se afirmar que em todas as bases de dados pesquisadas foi delimitado o período de dez anos para a recuperação das produções científicas que envolvessem o empreendedorismo informacional, ou seja, de 2008 a 2018. $\mathrm{Na}$ base de dados internacional a busca foi realizada com termos em inglês, enquanto que nas nacionais, os termos foram empregados em português.

\section{RESULTADOS}

\subsection{Produção Científica em Empreendedorismo Informacional NA CiênCIA dA INFORMAÇÃO}

A Tabela 1 apresenta os dados obtidos por meio da pesquisa dos termos "empreendedorismo informacional" AND "ciência da informação" nas bases de dados SciELO e BRAPCI, no período de 2008 a 2018. Além disso, optou-se por utilizar aspas duplas para que o sistema da base de dados recuperasse os termos exatamente da forma como foram inseridos. 
Como mostra a tabela, a pesquisa retornou apenas um trabalho, encontrado na BRAPCl, com o título: "Rede de tecnologia do Amazonas: fonte informacional para tomada de decisão". Todavia, mediante análise deste trabalho, não foi encontrado o termo 'empreendedorismo informacional', mas apenas 'empreendedorismo'. Na base de dados SciELO não foi encontrada nenhuma produção científica.

Termos pesquisados: "empreendedorismo informacional" AND "Ciência da Informação"

\section{Tabela 1 - Produção Sobre Empreendedorismo Informacional em Bases de Dados Brasileiras}

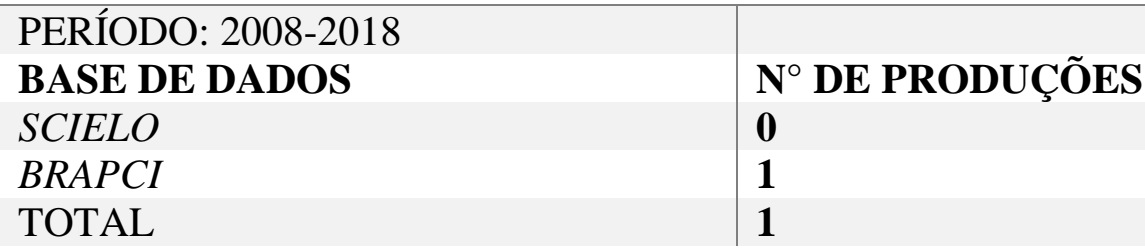

Fonte: Dados da Pesquisa (2019).

Conforme apontado pela Tabela 1, existem poucas produções no Brasil sobre o tema do empreendedorismo informacional. Esse fato reforça a justificativa do artigo ao apontar a lacuna de conhecimento científico. Por isso, esses resultados sugerem oportunidades de investigação para os pesquisadores brasileiros tanto da área da Ciência da Informação quanto da Administração.

A Tabela 2 apresenta os dados obtidos por meio da pesquisa dos termos "information entrepreneurship" AND "information science" na base de dados LISA, no período de 2008 a 2018. Também escolheu-se utilizar aspas duplas entre os descritores para que o sistema da base de dados recuperasse os termos precisamente da maneira como foram inseridos.

A busca retornou nove trabalhos, no entanto, em apenas dois o termo empreendedorismo informacional foi encontrado. Mesmo assim, desses dois, cujo títulos são, respectivamente: "Students' perceptions of the infopreneurship education in the Department of Records and Archives Management at the National University of Science and Technology" e "Trends, challenges and opportunities for LIS education and training in Eastern and Southern Africa"; nenhum trabalha essencialmente com 0 tema do empreendedorismo 
informacional como parte e/ou processo do campo científico da $\mathrm{Cl}$. Concomitantemente, interpretou-se que, de modo indireto, abordam que o empreendedorismo informacional pode auxiliar no fornecimento de habilidades práticas dos princípios da gestão da informação e do conhecimento nas organizações e novos empreendimentos, porém, a ideia não é foco dos trabalhos (OCHOLLA; BOTHMA, 2007; DEWAH; MUTULA, 2016).

Termos pesquisados: "Information Entrepreneurship" AND "Information Science"

Tabela 2 - Produção Sobre Empreendedorismo Informacional na Base de Dados Internacional

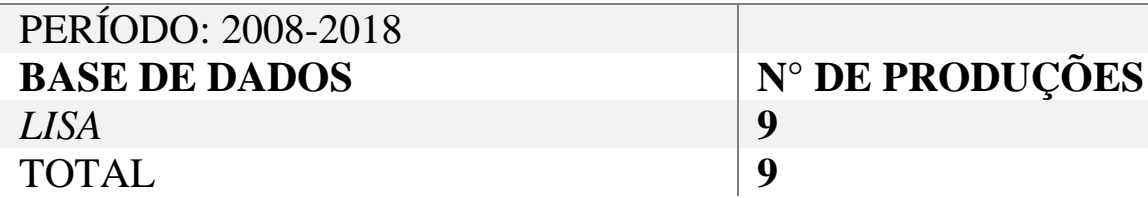

$\mathbf{N}^{\circ}$ DE PRODUÇÕES 9 9

Fonte: Dados da Pesquisa (2019)

Com isso, mediante a Tabela 2 e a análise realizada nos trabalhos retornados, pode-se enfatizar que praticamente não há produções internacionais sobre o tema do empreendedorismo informacional alicerçado pelo campo da $\mathrm{Cl}$, mas que existem inferências que podem estar ansiando pelo desenvolvimento deste tema, como forma de alavancar os processos da gestão da informação e da gestão do conhecimento, por exemplo, que já são um pouco mais amadurecidos na área, mas que a todo o momento sofrem interferências e modificações para aperfeiçoamentos necessários.

Portanto, o empreendedorismo informacional é um novo conceito de potencial investigativo na Ciência da Informação que evidencia a informação como elemento gerador de conhecimento e inovação. Ademais, essa abordagem - da informação como recurso que gera inovação e conhecimento nas organizações - é apoiada por pesquisadores brasileiros da área, como Valentim (2004), Hoffmann e Chemalle (2006), Damian (2015), entre outros.

\subsection{EMPREENDEDORISMO INFORMACIONAL COMO SUPORTE À GESTÃO DA INFORMAÇÃO}

Compreender o conceito de gestão da informação, seu contexto e como 
seus processos podem ser aplicados na prática é a principal maneira de tornar mais claro e acessível o conceito de empreendedorismo informacional. Pode-se apontar que com o empreendedorismo informacional, a gestão da informação pode ser desenvolvida com mais afinco e direcionada como um processo que auxilia na obtenção de lucros.

As empresas enfrentam, ainda nos tempos atuais, muitas dificuldades para aplicação das etapas/processos da gestão da informação, e esse fator acontece por alguns motivos que são derivados de muitas ausências, tais quais: ausência de engajamento dos sujeitos organizacionais em aplicar a gestão da informação no dia a dia da organização, ausência de uma cultura informacional efetiva, ausência de inovação e proatividade dos sujeitos organizacionais, ausência da capacidade dos sujeitos organizacionais em transformar problemas em soluções e ausência da visão de que a aplicação da gestão da informação pode render aumento dos lucros a curto, médio e longo prazo.

O empreendedorismo informacional pode ser considerado uma espécie de comportamento informacional baseado na inovação, ou seja, não há necessariamente a necessidade de criar um novo mecanismo para se gerenciar a informação presente no ambiente organizacional, mas sim a necessidade em inovar os processos e as etapas da gestão da informação, pois, apenas a consciência de que a informação e o seu gerenciamento são importantes não basta. Dentro disso, o empreendedorismo informacional possui um aglomerado de práticas e pré-requisitos que promovem a ação prática e inovadora da gestão da informação.

Concomitantemente, infere-se que o empreendedorismo informacional, quando utilizado no ambiente das organizações, contribui para uma aplicação muito mais consciente, eficiente e otimizada da gestão da informação e que leva em consideração suas reais demandas e necessidades informacionais. Além do mais, o empreendedorismo informacional colabora para a erradicação da ideia de que a aplicação da gestão da informação se faz pelas empresas apenas com o intuito de transparecer como organizações que se encontram adequadas às transformações da sociedade da informação e do conhecimento. Então, o empreendedorismo informacional é um processo que transforma as ações 
voltadas à gestão da informação como aquelas que vão de fato auxiliar na retenção dos lucros.

Segundo Ponjuán Dante (2011), a gestão da informação influencia nos ganhos econômicos de uma organização, pois é um tipo de gestão realizada para a manutenção dos recursos de informação, e que evita retrabalhos no processo produtivo de produtos e serviços.

Para Valentim (2004), a gestão da informação é definida como um conjunto de estratégias para identificação das necessidades informacionais, mapeamento dos fluxos formais, coleta, filtragem, análise, organização, armazenamento e disseminação das informações para o desenvolvimento das práticas de trabalho e amparo nos processos decisórios. Essas estratégias definidas pela autora supracitada são fixadas como atividades base da gestão da informação, representadas no Quadro 1.

\section{Quadro 1 - Atividades Base da Gestão da Informação de Valentim}

\begin{tabular}{|c|}
\hline $\begin{array}{c}\text { Gestão da Informação } \\
\text { Âmbito } \\
\text { Fluxos Formais }\end{array}$ \\
\hline $\begin{array}{l}\text { Objeto } \\
\text { Conhecimento Explícito }\end{array}$ \\
\hline Atividades Base \\
\hline$\checkmark \quad$ Identificar demandas e necessidades de informação. \\
\hline Mapear e reconhecer fluxos formais. \\
\hline $\begin{array}{l}\checkmark \text { Desenvolver a cultura organizacional positiva em relação ao compartilhamento/socialização de } \\
\text { informação. }\end{array}$ \\
\hline $\begin{array}{l}\checkmark \text { Proporcionar a comunicação informacional de forma eficiente, utilizando tecnologias de } \\
\text { informação e comunicação. }\end{array}$ \\
\hline$\checkmark \quad$ Prospectar e monitorar informações. \\
\hline Coletar, selecionar e filtrar informações. \\
\hline $\begin{array}{l}\checkmark \text { Tratar, analisar, organizar, armazenar informações, utilizando tecnologias de informação e } \\
\text { comunicação. }\end{array}$ \\
\hline $\begin{array}{l}\checkmark \text { Desenvolver sistemas corporativos de diferentes naturezas, visando o compartilhamento e uso } \\
\text { da informação. }\end{array}$ \\
\hline Elaborar produtos e serviços informacionais. \\
\hline$\checkmark$ Fixar normas e padrões de sistematizacão da informacão. \\
\hline$\checkmark$ Retroalimentar o ciclo. \\
\hline
\end{tabular}

Fonte: Valentim (2004)

Detlor (2010) corrobora em partes e afirma que a gestão da informação

[...] é a gestão dos processos e sistemas que criam, adquirem, organizam, armazenam, distribuem e utilizam informações. 0 objetivo da gestão da informação é ajudar as pessoas e as organizações no acesso, processo e uso da informação de forma eficiente e eficaz (DETLOR, 2010, p.103). 
Marchiori (2014) define a gestão da informação como um processo que demanda algumas decisões fundamentadas na representação da informação, na escolha de sistemas de armazenamento de dados e informações, na qualidade das fontes de informação utilizadas pelos sujeitos organizacionais, nas maneiras de acesso a essas fontes, no compartilhamento e transmissão da informação e na avaliação do uso e reuso informacional.

De acordo com Schumpeter (1988), o empreendedorismo configura-se em um processo de desconstrução e construção criativa, em que produtos, métodos, serviços e processos já existentes são destruídos, modificados e substituídos por novos.

À vista disso, com o intuito de demonstrar como o processo do empreendedorismo informacional pode contribuir para a gestão da informação, desenvolveu-se um quadro com a disposição de etapas/processos do empreendedorismo informacional com base nas atividades base da gestão da informação de Valentim (2004). Isto é, o Quadro 2 determina como os sujeitos organizacionais podem aplicar a gestão da informação com base no empreendedorismo informacional e nas características asseveradas por este processo.

\section{Quadro 2 - Etapas do Empreendedorismo Informacional para Gestão da Informação}

\begin{tabular}{|c|}
\hline $\begin{array}{c}\text { Empreendedorismo Informacional } \\
\text { Âmbito } \\
\text { Fluxos Formais e Informais }\end{array}$ \\
\hline $\begin{array}{l}\text { Objeto } \\
\text { Conhecimento Tácito e Explícito }\end{array}$ \\
\hline Etapas \\
\hline $\begin{array}{l}\checkmark \text { Definir metas e dúvidas sobre o processo produtivo e as maneiras para alcançá-las e responde- } \\
\text { las. }\end{array}$ \\
\hline$\checkmark \quad$ Analisar processos e maneiras eficientes para a solução de problemas. \\
\hline$\checkmark \quad$ Motivar os sujeitos organizacionais e agir em conjunto. \\
\hline $\begin{array}{l}\checkmark \text { Expor dificuldades e erros para aprendizado e utilizar o conhecimento dos outros sujeitos } \\
\text { organizacionais para escolha de soluções. }\end{array}$ \\
\hline $\begin{array}{l}\checkmark \quad \text { Utilizar e ser capacitado(a) para o uso das tecnologias de informação e comunicação e sistemas } \\
\text { de informação da empresa. }\end{array}$ \\
\hline $\begin{array}{l}\checkmark \text { Prospectar, monitorar, selecionar, organizar e armazenar as informações coletadas com os } \\
\text { sujeitos organizacionais e com o uso de tecnologias de informação e comunicação. }\end{array}$ \\
\hline$\checkmark \quad$ Avaliar a informação coletada para definição de estratégias e tomadas de decisões. \\
\hline $\begin{array}{l}\checkmark \text { Criar documentos com perguntas e respostas dos sujeitos organizacionais sobre os } \\
\text { procedimentos do processo produtivo da empresa. }\end{array}$ \\
\hline
\end{tabular}


Fixar normas e padrões de sistematização da informação coletada com os sujeitos organizacionais e com os sistemas de informação.

Fonte: Elaborado pelas autoras (2019)

De acordo com Baggio e Baggio (2014), o empreendedorismo é um comportamento importante para o processo de desenvolvimento econômico do país e seus vieses incentivam e levam em consideração um comportamento mais prático e inovador dos indivíduos envolvidos com o empreendedorismo.

As etapas do empreendedorismo informacional presentes no Quadro 2, são altamente direcionadas ao equilíbrio e eficácia das etapas da gestão da informação, nesse caso, estipuladas por Valentim (2004). Optou-se por utilizar as atividades base da gestão da informação da autora (2004), porque configurase em um modelo de gestão da informação mais adaptado ao ambiente organizacional, bem como um dos mais atuais e mais utilizados na literatura da Ciência da Informação brasileira.

O empreendedorismo informacional trabalha nos âmbitos do fluxo formal e informal de informação, e, por isso, possui como objeto o conhecimento tácito e o conhecimento explícito, concomitantemente. $O$ empreendedorismo informacional corresponde a um processo que visa considerar os produtos e serviços de informação, independentemente de esses estarem materializados como objetos explícitos ou não, afinal o seu processo é um apoiador de outros processos relacionados ao gerenciamento da informação e conhecimento.

Para cada atividade base descrita por Valentim (2004) foi estipulada uma etapa que pudesse contemplar o desenvolvimento efetivo da gestão da informação, baseada nas características tradicionais do empreendedorismo. Conforme Pati (1995), o empreendedorismo se estabelece mediante algumas características, que são: (i) motivação pelo desejo de realizar; (ii) capacidade de análise de riscos e oportunidades; (iii) liberdade no ato de agir, definir objetivos e métodos para atingi-los; (iv) autoconfiança; (v) ação em grupo; (vi) resistência para o enfrentamento de dificuldades; (vii) capacidade de ser otimista e realista ao mesmo tempo; (viii) flexibilidade e administração das necessidades; (ix) aprendizado baseado em erros e dificuldades; $(x)$ habilidades em manter relações interpessoais e de se comunicar com equilíbrio; (xi) criatividade na solução de problemas; (xii) valorização do conhecimento do outro e do próprio 
conhecimento (xiii) valorização da qualidade; (xiv) capacidade de administrar bem o tempo; (xv) busca pela contribuição social; (xvi) competência para 0 desenvolvimento e captação de recursos e informação necessárias, entre outras. Como pode ser notado, o empreendedorismo sustenta consigo inúmeras características que podem subsidiar a otimização e o desenvolvimento dos processos da gestão da informação no ambiente organizacional, o que inclui o uso consciente da informação com qualidade nas práticas de trabalho e processos decisórios.

A definição de metas e o registro de dúvidas relativas ao trabalho são maneiras interessantes para identificação das necessidades informacionais. Enquanto isso, a busca por novos procedimentos, respostas para o alcance das metas e resolução das dúvidas, respectivamente, também devem ser registradas. A análise dos processos, dos métodos e das respostas utilizadas para solução de problemas faz-se como uma maneira mais específica e direta para a prática do mapeamento da informação.

Para o desenvolvimento de uma cultura organizacional voltada ao compartilhamento da informação, sugere-se que os sujeitos organizacionais sejam motivados a trabalhar em grupo. Indica-se que mesmo quando a atividade não envolva trabalho em grupo, que os sujeitos saibam agir em conjunto, por meio da valorização de opiniões diversas. Como incentivo a comunicação, é possível criar momentos para exposição de erros encontrados, a fim de que todos aprendam com suas próprias dificuldades e dificuldades alheias, e que simultaneamente passem a utilizar o conhecimento dos outros sujeitos organizacionais para o desenvolvimento de tarefas.

Antes de qualquer capacitação voltada aos processos de tratamento e organização da informação por meio das tecnologias de informação e comunicação, o empreendedorismo informacional promove a capacitação e a utilização dos sistemas de informação da empresa e envolve todos os funcionários. Assim, as etapas de prospecção, monitoramento, seleção, organização, armazenamento, coleta e avaliação somente deverão ser implantadas para capacitação a partir do instante em que os sujeitos organizacionais estiverem imersos em um relacionamento mais intimista com esses sistemas. 
De uma maneira geral, a fim de amparar a atividade base que corresponde a elaboração de produtos e serviços de informação, recomenda-se que os indivíduos das organizações criem documentos que contenham perguntas e respostas a respeito dos procedimentos que se relacionam com 0 processo produtivo da empresa. Esse documento é um tipo de produto/serviço de informação, oriundo de práticas dos próprios funcionários, que devem ser orientados a registrarem suas dificuldades, dúvidas, necessidades, metas e ao mesmo tempo as respostas, métodos e soluções obtidos para tais.

Acredita-se que o desenvolvimento deste documento contribui para a valorização do capital intelectual da empresa ao mesmo tempo em que desenvolve a preservação da memória organizacional, como afirmam Santos e Damian (2018). Ademais, menciona-se que todas as etapas citadas resultam na sistematização da informação, coletadas tanto por intermédio do capital humano quanto por via do capital tecnológico, e, portanto, além de processos que colaboram com a execução da gestão da informação no ambiente organizacional, podem ser denominadas como normas e padrões para sistematização da informação.

Desse modo, o empreendedorismo informacional se traduz em comportamentos e competências de busca de informação. Torna-se relevante subsídio ao processo de gestão da informação a medida que enfrenta os desafios informacionais presentes na organização. O empreendedor foca na aplicação prática dos processos e como estabelecer metas para se alcançar a estratégia empresarial.

A informação que gera conhecimento (VALENTIM, 2004) é elemento que soluciona problemas e gera outros novos, pois o ambiente empresarial está em constante mudança, principalmente no contexto atual que preza a inovação. Durante a gestão da informação, os indivíduos podem sofrer sentimentos de dúvidas, ansiedade, preocupação, aumentando o seu nível de stress. É nesse momento que o empreendedorismo informacional norteia as pessoas a lidarem com sabedoria e direcionar as ações no processo de gestão da informação.

Portanto, o ambiente que gerencia a informação de modo efetivo envolve e inter-relaciona diversos elementos de um ambiente organizacional, em prol da 
execução de atividades relativas à gestão da informação. As etapas do empreendedorismo informacional podem ser norteadores durante essa gestão para que os indivíduos tenham confiança em suas ações de busca de informação e tomada de decisão. Tais etapas possibilitam a inovação do modo de trabalho, isto é, do saber-fazer das pessoas e estimula a aprendizagem por meio da informação.

O modelo de gestão da informação de Ponjuán Dante (2011) demonstra que todos os elementos de um ambiente organizacional (recursos humanos e tecnológicos, serviços e processos produtivos, sistemas de informação, cultura organizacional e informacional, entre outros) trabalham em conjunto, são responsáveis e devem ser levados em consideração na realização da gestão da informação, que também depende de competências e habilidades informacionais dos indivíduos.

Figura 1 - Modelo de Gestão da Informação de Ponjuán Dante

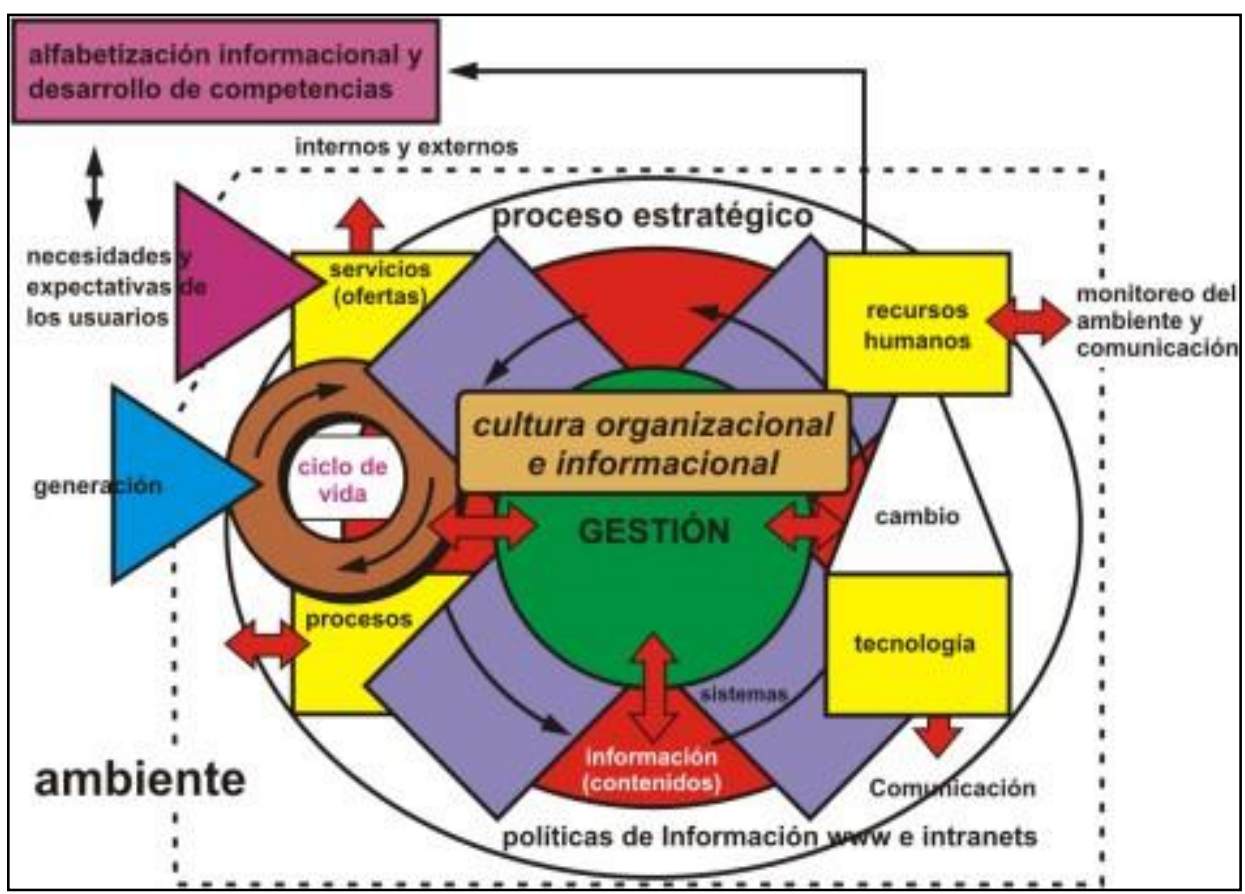

Fonte: Ponjuán Dante (2011)

Para Ponjuán Dante (2011, p.14) gestão da informação é

[...] um processo estratégico que ocorre em uma organização de qualquer tipo (incluindo comunidades e outras entidades de natureza social). E um processo que engloba todos os processos e atividades dessa organização e seus componentes, por isso tem um relacionamento próximo com o sistema que a governa. (PONJUÁN DANTE, 2011, p.14, tradução nossa). 
Por essa citação da autora (2011), é possível inferir que, ao se realizar a gestão da informação em uma organização, torna-se importante que os indivíduos compreendam, de modo generalizado, que o protagonismo e o uso consciente da informação estão nas entrelinhas das práticas organizacionais e que, muitas vezes, não costumam estar evidentes aos olhos dos sujeitos. Portanto, a prática do processo de gestão da informação necessita acontecer de modo intencional e diário, baseado em uma característica empreendedora e criativa, em que se busca articular planos estratégicos para o gerenciamento da informação.

A gestão da informação efetiva é dependente dos esforços de todos os setores de uma organização, bem como dos seus recursos: humanos, tecnológicos, financeiros, sociais e ambientais, que juntos geram os inputs necessários para o sucesso do processo produtivo. Além disso, a Figura 2 procura representar que as etapas do empreendedorismo informacional (Quadro 2) devem ser realizadas por todos os setores organizacionais e devem estar presentes na otimização e nas maneiras de utilização dos recursos.

Figura 2 - Gestão da informação baseada no Empreendedorismo informacional

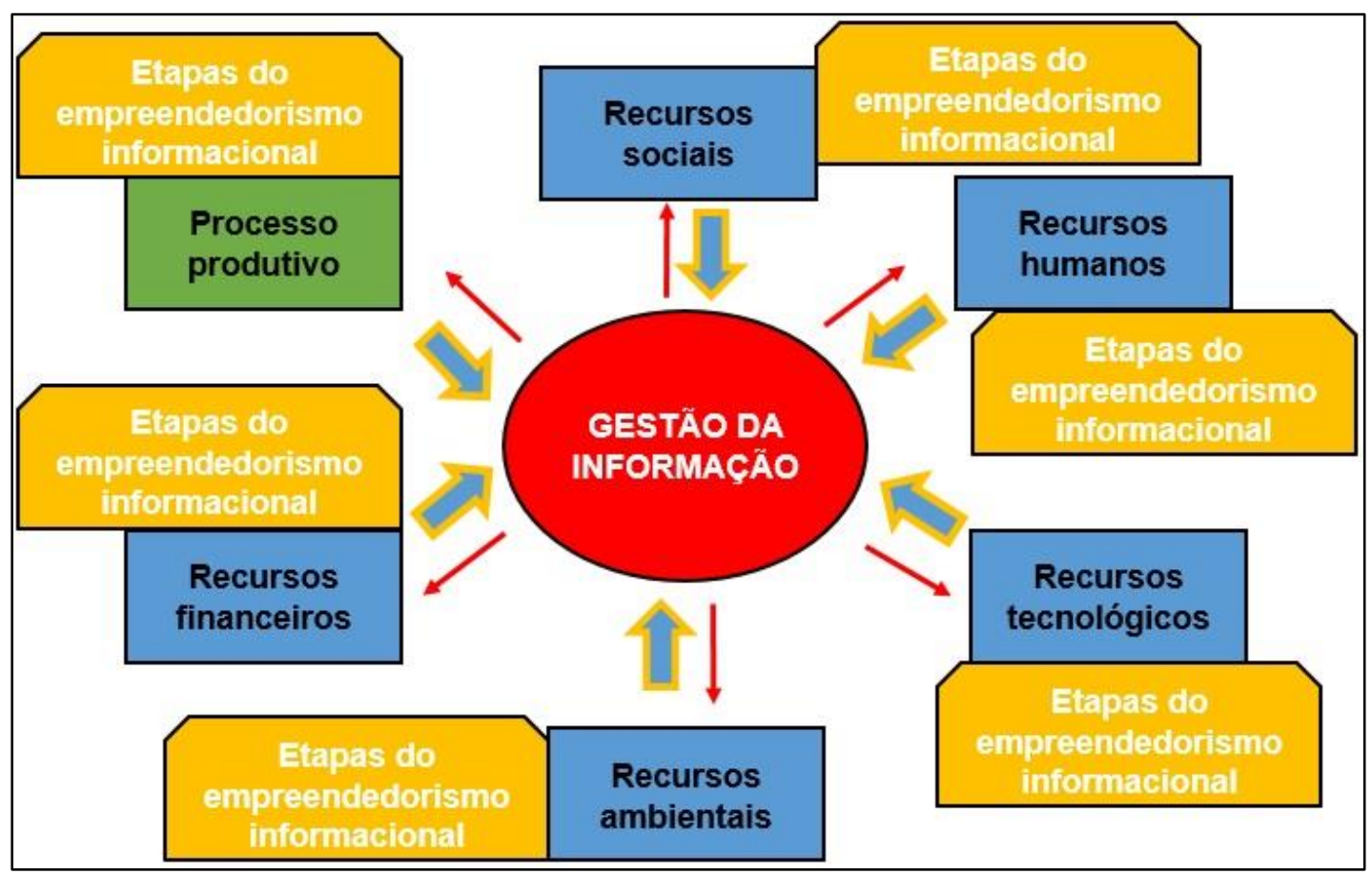

Fonte: Elaborado pelas autoras (2019)

Portanto, os recursos e os setores responsáveis pelo funcionamento do 
processo produtivo, quando praticados em sinergia, e com base nas etapas do empreendedorismo informacional, são capazes de desenvolver com eficácia o processo da gestão da informação, que, então, alcança o bom desenvolvimento dos setores e a melhor utilização dos recursos supracitados.

Obviamente, pode-se afirmar que a gestão da informação contribui para a melhor utilização da própria informação, também tida como um recurso, mas que na Figura 2 não se transcende em evidência, mas nas entrelinhas, como um recurso inserido no contexto dos demais recursos tradicionais (sociais, humanos, tecnológicos, ambientais e financeiros), presente em abundância e sempre de modo natural em qualquer lugar e circunstância.

\section{CONSIDERAÇÕES FINAIS}

O empreendedorismo informacional está relacionado com a criação de novos negócios e procedimentos no processo produtivo e de serviço, com base no uso da informação para a construção de conhecimento e geração de maiores lucros. O conhecimento é peça chave para a geração de novas ideias e inovação. Esse empreendedorismo conta com conceitos advindos da área da Administração e da Ciência da Informação, por isso, é considerado interdisciplinar.

A análise cientométrica demonstrou que os estudos ainda são escassos por ambas as áreas científicas e, portanto, existem oportunidades de pesquisa sobre a temática. Além disso, demonstrou-se a inter-relação entre 0 empreendedorismo informacional com a gestão da informação. Essa conexão contribui para que as organizações se tornem mais competitivas, e, assim, compreendam o valor tanto do processo de empreendedorismo informacional como do processo de gestão da informação.

Pode-se apontar que ao empreender, o indivíduo possui acesso à quantidade massiva de informação, e, a partir delas, constrói conhecimento sobre novas soluções e negócios. As considerações finais apontam a necessidade de estudos mais aprofundados e sua aplicação prática em organizações que se utilizam da gestão da informação, tendo em vista que o 
empreendedor necessita gerir estas informações sobre as oportunidades do mercado para tomar decisão.

Nesse trabalho, abordou-se as características do empreendedorismo informacional voltado à gestão da informação, no entanto, não se descarta a possibilidade do empreendedorismo informacional direcionado à gestão do conhecimento, uma vez que o próprio conhecimento advém de um processo informacional. Essa aplicação pode ser uma sugestão a pesquisas futuras.

\section{REFERÊNCIAS}

BAGGIO, A.F.; BAGGIO, D.K. Empreendedorismo: conceitos e definições. Rev. de Empreendedorismo, Inovação e Tecnologia, n.1, v.1, p.25-38, 2014. Disponível em: https://seer.imed.edu.br/index.php/revistasi/article/view/612. Acesso em: 27 dez. 2018.

BORKO, H. Information Science: What is it? American Documentation, v.19, n.1, p.3-5, Jan. 1968.

CALLON, M.; COURTIAL, J.; PENAN H. Cientometría: la medición de la actividad científica de la bibliometría a la vigilancia tecnológica. Gijón: Trea, 1995.

DETLOR, B. Information Management. International Journal of Information Management, v.3, n.2, p.103-108, 2010. Disponível em: https://www.sciencedirect.com/journal/international-journal-of-informationmanagement/vol/30/issue/2. Acesso em: 12 set. 2017.

CAPURRO, R.; HJORLAND, B. O Conceito de Informação. Perspectivas em ciência da informação, v.12, n.1, jan./abr. p. 148-207, 2007.

CASTELLS, Manuel. A sociedade em rede. 8 Ed. São Paulo: Paz e Terra, 2005.

DAMIAN, I.P.M. A importância das tarefas e os fatores críticos de sucesso para o gerenciamento de processos de negócios. Revista de Administração da UNIMEP, v.13, n.2, Maio/Ago, 2015. Disponível em: https://www.redalyc.org/html/2737/273741070008/. Acesso em: 03 jan. 2019.

DEWAH, P.; MUTULA, S. Students' perceptions of the infopreneurship education in the Department of Records and Archives Management at the National University of Science and Technology. South African Journal of Information Management, v.18, n.1, 2016. Disponível em: https://sajim.co.za/index.php/sajim/article/view/717. Acesso em: 02 jan. 2019. 
FONSECA, J.J.S. Metodologia da pesquisa científica. Fortaleza: UEC, 2002. Apostila.

HISRICH, R. D.; PETER, M. P. Empreendedorismo. Porto Alegre: Bookman, 2004.

HOFFMANN, W. A. M.; CHEMALLE, K. E. Acesso e uso de inteligência competitiva em micro e pequena empresas de arranjos produtivos locais. In: ENCONTRO NACIONAL DE PESQUISA EM CIÊNCIA DA INFORMAÇÃO, 7,2006, Marilia. Anais [...]. Marilia, v. 7. p. 1-12, 2006.

LOGAN, Robert K. O que é informação? A propagação da organização na biosfera, na simbolosfera, na tecnosfera e na econosfera. Rio de Janeiro: contraponto: PUC-Rio, 2012.

MARCHIORI, P.Z. Gestão da informação: fundamentos, componentes e desafios contemporâneos. In: SOUTO, L.F. (org.). Gestão da informação e do conhecimento: práticas e reflexões. Rio de Janeiro: Interciência, 2014, p.2745.

OCHOLLA, D.; BOTHMA, T. Trends, challenges and opportunities for LIS education and training in Eastern and Southern Africa. New Library World, v.108, n.1/2, pp.55-78, 2007. Disponível em:

https://doi.org/10.1108/03074800710722180. Acesso em: 02 jan. 2019.

OTTONICAR, S. L. C. Análise teórico-descritiva da competência em informação de gestores como fator de competitividade das indústrias de eletroeletrônicos da cidade de Garça/SP. 271 f. Dissertação (Mestrado) Faculdade de Filosofia e Ciências, Universidade Estadual Paulista, Marília, 2016.

PONJUÁN DANTE, G. La gestión de información y sus modelos representativos. Valoraciones. Ciencias de la Información, v.42, n.2, p.11-17, 2011. Disponível em: http://www.redalyc.org/articulo.oa?id=181422294003. Acesso em: 19 nov. 2018.

SANTOS, B.R.P.; DAMIAN, I.P.M. Diretrizes para preservação da memória organizacional mediante a valorização do capital intelectual e da gestão do conhecimento. In: CARVALHO NETO, S.; SMITH, M.S.J.; OLIVEIRA, P.T

(org.). XIX Encontro de Pesquisadores: pesquisa científica e desenvolvimento. Franca: Uni-FACEF, 2018, p.841-856.

SARACEVIC, T. Interdisciplinarity nature of Information Science. Ciência da Informação, Brasília, v.24, n.1, p. 36-41, 1995.

SCHUMPETER, J.A. A teoria do desenvolvimento econômico. São Paulo: Nova Cultura, 1988. 
SILVA, J. L. C.; FREIRE, G. H. A. Um olhar sobre a origem da ciência da informação: indícios embrionários para sua caracterização identitária.

Encontros Bibli: revista eletrônica de biblioteconomia e ciência da informação, v. 17, n. 33, p. 1-29, jan./abr., 2012. ISSN 1518-2924. DOI: 10.5007/15182924.2012v17n33p1.

VALENTIM, M.L.P. Gestão da informação e gestão do conhecimento: especificidades e convergências. Londrina: Infohome, 2004 (Artigo em Web). Disponível em: http://www.ofaj.com.br/colunas_conteudo.php?cod=88. Acesso em: 05 jun. 2017.

ZARPELLON, S. C. O empreendedorismo e a teoria econômica institucional. Revista Iberoamericana de Ciências Empresariais y Economia, vol.1, n.1, p. 47-55, 2010.

\title{
PERSPECTIVES ABOUT INFORMATION ENTREPRENEURSHIP IN INFORMATION SCIENCE FIELD
}

\begin{abstract}
Introduction: The paper aims to discuss the topic of information entrepreneurship as a new process of the Information Science field. This paper has the following research questions: what is information entrepreneurship? Can information entrepreneurship contribute to the information management process? The methodology has a qualitative and quantitative approach, and it uses the bibliographic analysis and scientometric analysis to demonstrate how information entrepreneurship is studied in the Information Science field. Furthermore, this paper connects information entrepreneurship to information management. The results showed that studies are still scarce in the area and, therefore, there are opportunities for research on the subject. In addition, it demonstrated the interrelationship between information entrepreneurship and information management, and how this connection helps organizations to become more competitive. The conclusions show that information entrepreneurship is related to the creation of new businesses in the production process and services, through the use of information to construct knowledge.
\end{abstract}

Keywords: Information entrepreneurship. Information management. Information Science. Scientometric Analysis.

\section{PERSPECTIVAS SOBRE EL EMPRENDIMIENTO INFORMATIVO EN CIENCIAS DE LA INFORMACIÓN}

\section{RESUMEN}

Introducción: El artículo tiene como objetivo iniciar discusiones sobre el tema del emprendimiento informacional como un nuevo proceso de la Ciencia de la Información. Este objetivo está relacionado con las siguientes preguntas: ¿qué es el emprendimiento 
informativo? ¿Puede el emprendimiento informativo contribuir al proceso de gestión de la información? La metodología es de carácter cualitativo y cuantitativo, de tipo descriptivo-exploratorio, que utiliza las técnicas de análisis bibliográfico y análisis cienciométrica para demostrar cómo se aborda el emprendimiento informacional desde las Ciencias de la Información, así como su relación con el manejo de la información. Los resultados mostraron que los estudios aún son escasos en el área y, por lo tanto, existen oportunidades de investigación sobre el tema. Además, demostró la interrelación entre el emprendimiento informativo y la gestión de la información y en qué medida esta conexión contribuye a que las organizaciones sean más competitivas y obtengan mejores resultados. Las consideraciones finales señalan que el emprendimiento informacional está relacionado con la creación de nuevos negocios y procedimientos en el proceso productivo y de servicios, mediante el uso de la información para construir conocimiento y generar ganancias.

Palabras clave: Emprendimiento informativo. Gestión de la información. Ciencias de la Información. Análisis cienciométrica.

Recebido em: 16.09 .2020

Aceito em: 18.11 .2020 